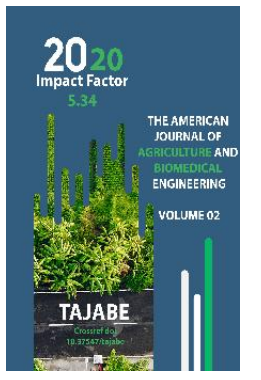

\title{
Influence Of Environmental Factors On The Formation Of The White Fly Population
}

Otabek Abdushukirovich Sulaymonov
Tashkent State Agrarian University, Uzbekistan

Journal Website:

http://usajournalshub.c

om/index,php/tajabe

Copyright: Original content from this work may be used under the terms of the creative commons attributes 4.0 licence.

\section{ABSTRACT}

In studies, the influence of environmental factors and plant species on the development and density of the population of the greenhouse whitefly has been studied. The change in the development of the pest population in the conditions of an average daily air temperature of $33,6^{\circ} \mathrm{C}$ and a relative humidity of $42 \%$ in the Syrdarya region and a temperature of $31,8^{\circ} \mathrm{C}$ and a relative humidity of $54 \%$ in the Tashkent region has been revealed. The highest pest population was observed in the cucurbitaceous culture.

\section{KEYWORDS}

Greenhouse whitefly, pest, population, environmental factors, relative air humidity, air temperature, vegetable crops.

\section{INTRODUCTION}

Despite many years of research by our scientists and the emergence of new types of plant protection products, it is outlined that effective methods of combating some types of pests are ineffective. Including in agriculture more than 200 vegetables and melons, more than 30 industrial crops, more than 60 species of ornamental crops and shrubs, affected by greenhouse whiteflies (Trialeurodes vaporariorum West.), Belonging 
to the family Aleyrodidae of the genus Homoptera, cotton whiteflies (Bemisia tabaci Genn and citrus whiteflies (Dialeurodes citri A.) cause serious damage. Consequently, the management of the number of these species requires the improvement of the development of effective environmentally friendly methods to combat them. In nature, scientists have not come to a final conclusion about the formation of parasitic host relationships. Since there are species of phytophages and species of entomophages of each species, on the contrary, they sometimes cannot control the number of harmful organisms, even if there are many of them. The optimum air temperature plays an important role in the development of whiteflies and their parasitic encarsia (Encarsia partenopea Masi), but each species has its own ecological characteristics.

There are several ecologically modified species of tobacco whiteflies or cotton whiteflies and greenhouse whiteflies that have been interpreted under several names. Each species has more than 10 species that are synonymous in science, including names given by local residents of a state or region. According to scientists, one of the main factors in the disproportion of the ratio of whiteflies and their parasites is the presence of various environmental environmental factors for their development, while some scientists suggest that for Encarsia partenopea Masi, a temperature of $25^{\circ} \mathrm{C}$ is favorable for the optimal development of the parasite type and unfavorable the air temperature is below $15^{\circ} \mathrm{C}$. In this case, high temperature conditions play an important role in the management of whitefly populations in an increase or a sharp decrease in their numbers. Such reasoning serves to discover the patterns that cause a sharp increase in the number of whiteflies. Such scientific research can also be conducted on the basis of environmental factors in pest control. For example, the development of the cotton whitefly (B.tabaci) is related to temperature (of course, the type of plant also plays an important role), temperature is an important factor in the relationship between the plant and the pest. In Egypt, the passage of one generation of whiteflies is shorter in summer (14-20 days) than in winter (in greenhouses 7475 days).

The development of one generation of pests at an air temperature of $26,7^{\circ} \mathrm{C}$, depending on the type of crop, the generation that feeds on cabbage and carrot leaves ends 30\% later in comparison with those that feed on lettuce, cucumber, eggplant and ipatisson leaves. The influence of environmental factors on the development of greenhouse whiteflies in various vegetable crops in our country has been studied. The aim is to determine the degree of influence of the ecological environment on the management of the number of pests, in order to study whether they depend on crop species in the event of sudden changes in the number of populations.

\section{MATERIALS AND METHODS}

The research was carried out on vegetable crops in open fields with different ecological environments. Syrdarya region (relatively xerophilic) and Tashkent region (relatively hygrophilic) were selected. For the study, cucumbers, pumpkins and melons were planted. Then, for experiments, they planted tomatoes, eggplants, bell peppers, etc., belonging to the tomato family, one hundred square meters each. The research used research methods in the field of entomology. During the study, the soil and climatic conditions of the region were also monitored. When growing vegetables and melons, the methods of B.D. Azimov (1995) were used. 
During the study, the low air temperature was $+22,4^{\circ} \mathrm{C}$, and the high air temperature was $44,6^{\circ} \mathrm{C}$. The relative humidity was below $32 \%$ and the high relative humidity was $67 \%$.

Research results. According to the experiments carried out, different results were obtained in variants. At the same time, the relative humidity and air temperature in both regions were monitored daily in the crops of the pumpkin family. Studies were carried out from May in the periods of leaf blooming, flowering, budding, fruiting, ripening. During the period when the night air temperature averaged $26^{\circ} \mathrm{C}$, the development of the whitefly population varied in different types of crops in different ways. The average air temperature in the Syrdarya region was $33,6^{\circ} \mathrm{C}$, the relative humidity was $42 \%$. At the same time, the types of crops infested with greenhouse whiteflies were monitored throughout the season.

Accordingly, the period with the highest number of the season was accounted for.
According to studies and observations, the average number of pests per 1 cucumber leaf is 62,2 , in melon it is comparatively more than 74,2 in pumpkin, 66,3 in watermelon, 44,3 in tomato 42,7 and eggplant. 63,1 pieces, 36,6 pieces in bell peppers, 53,6 pieces in cabbage and an average of 28,5 pieces on a carrot leaf. In the course of the study, calculations of greenhouse whiteflies were performed only taking into account the imago of the pest. At the same time, the crop yield sharply decreased compared to the control, and the seasonal plant growth was shorter than the control for several days.

The control variant was protected with a special entomological mesh and ensured that the crops were not damaged by whiteflies and other pests. For example, in our variant, the infected crops of cucumbers by pests died in 20 days in comparison with the control. Similar cases have been observed in other cultures.

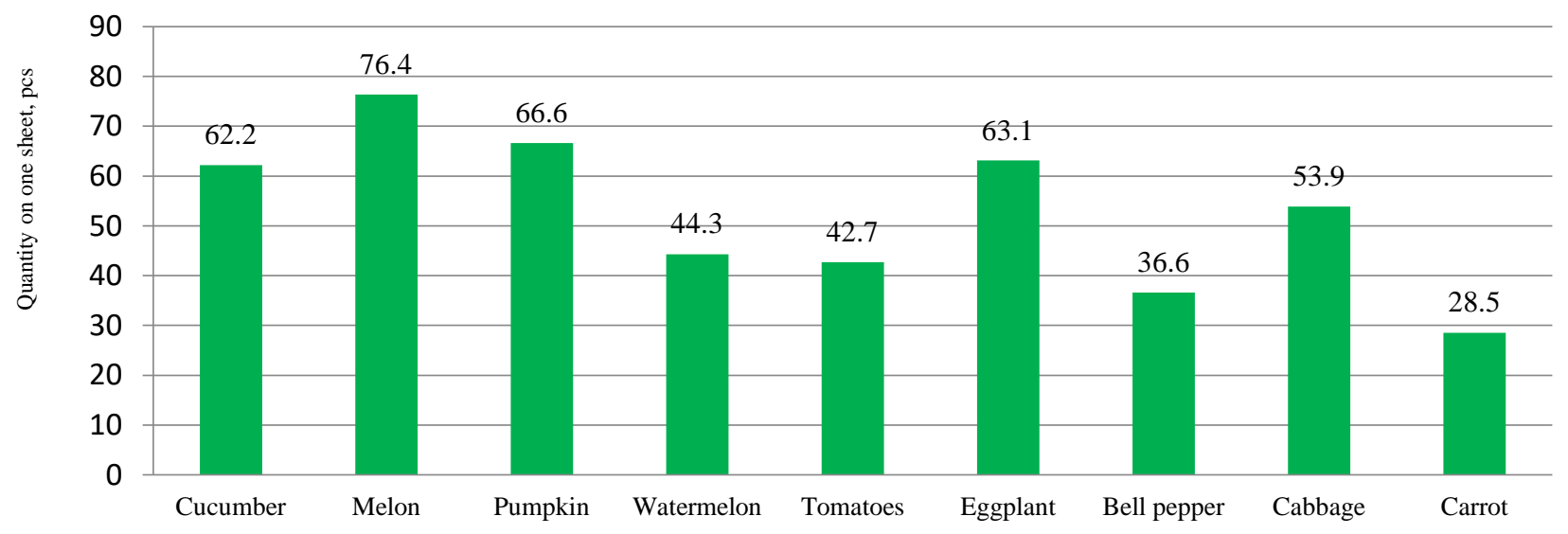

Fig-1. Development of greenhouse whiteflies by types of crops in the Syrdarya region (average air temperature $33,6^{\circ} \mathrm{C}$, relative humidity $42 \%$ )

Our next study showed that the average air temperature in the Zangiata district of the Tashkent region was $31,8^{\circ} \mathrm{C}$, and the relative humidity was 54\%. Climatic conditions were slightly different from previous observations. In addition, the development of agricultural 
crops was active. Of course, the high level of alkalinity in the soil of the Syrdarya region may have caused the difference between the two.

At the same time, the types of crops infested with greenhouse whiteflies were subject to seasonal monitoring, and the largest population was observed in melon ( 82,8 units) and pumpkin ( 83,2 units). Other species have 76,5 pieces for cucumber, 52,4 pieces for watermelon, 48,3 pieces for tomatoes, 72,1 pieces for eggplant, 51,6 pieces for sweet peppers, 42,7 pieces for cabbage and in one carrot leaf increased by 33,8 pieces on average. These differences can be observed in different climatic conditions and especially in the effect of relative humidity. Relative humidity also plays an important role in the development of greenhouse whiteflies. Differences were observed across regions, especially in terms of types of cultures.

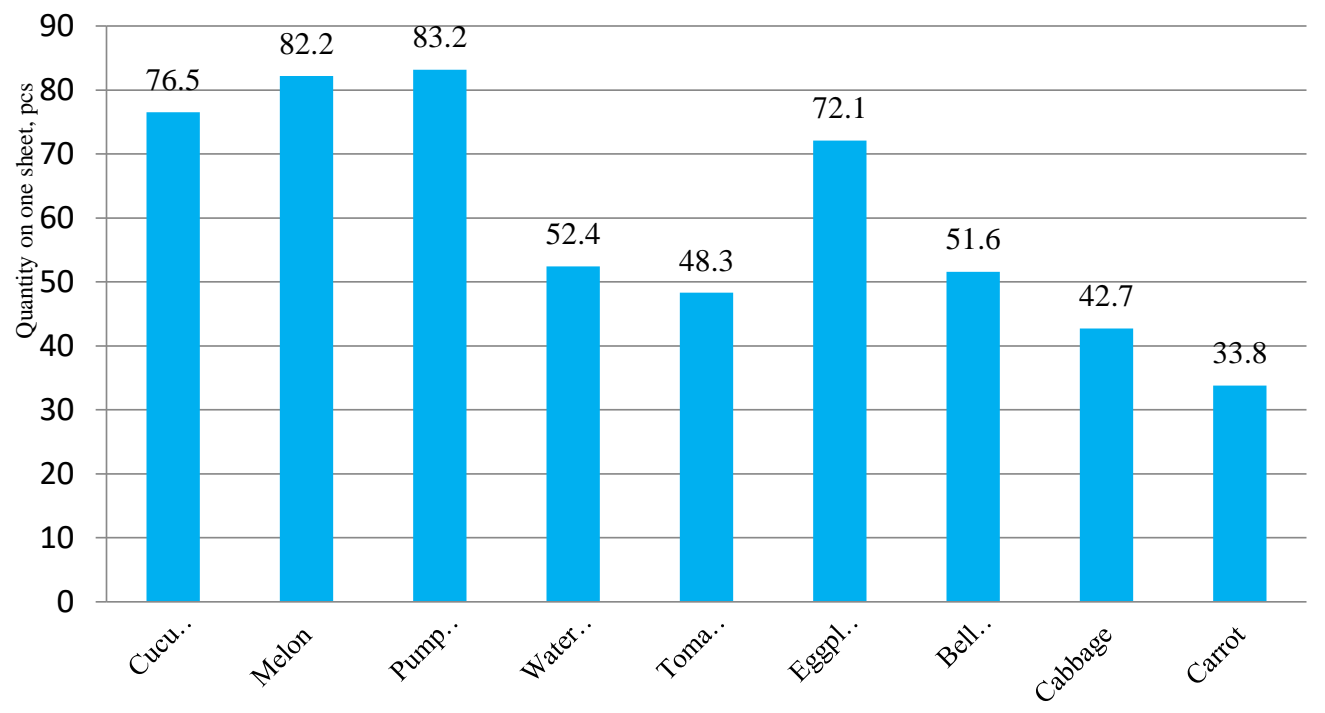

Fig-2. Development of greenhouse whiteflies by types of crops in the conditions of Tashkent region (average air temperature $31,8^{\circ} \mathrm{C}$, relative humidity 54\%)

For example, 53.9 units of the pest were found in cabbage at $33.6^{\circ} \mathrm{C}$ and $42 \%$ relative humidity, while 42.7 units were found in other species at $31.8^{\circ} \mathrm{C}$ and $54 \%$ relative humidity. observable. The relatively smallest abundance was observed in the study in carrots. However, it turned out that eggplant was the most affected by greenhouse whiteflies among the tomato families.

\section{CONCLUSION}

Based on the obtained results, the study concludes that the ecological environment and types of crops in each region affect the development of greenhouse whiteflies. The environment, depending on soil and climatic conditions, the correct placement of varieties and types of crops, the optimal amount of 
water can create unfavorable conditions for the development of greenhouse whiteflies. Relatively good development was observed, especially in crops belonging to the tomato family.

\section{REFERENCES}

1. Azimov B.D. Technology of tomato varieties in Uzbekistan. -Toshkent, Fan, 1995. -244 P.

2. Striganova B.R., Zakharov A.A. A fivelanguage dictionary named animals: Insects (Latin - Russian - English - German - French). Ed. Dr. bio. Science. B.R.Striganova- M: RusSO, 2000, p-49.

3. Kimsanboev Kh.Kh., Zakhidov FM, Kadyrov A. Whiteflies and their entomophages. Tashkent. JSC AgroIndustrial Information.1997. - $\mathrm{p} 17$.

4. Ashfaq M., Ane M.N.U., Zia K., Nasreen A., Hasan M.U. The correlation of abiotic factors and physico-morphic charateristics of (Bacillus thuringiensis) Bt transgenic cotton with whitefly, Bemisia tabaci Homoptera: Aleyrodidae and jassid, Amrasca devastans Homoptera: Jassidae populations. African Journal of Agricultural Research. 2010; 5 (22): 31023107.

5. AzabA.K., Megahed M.M. and El Mirsawi H.D. Studieson Bemisia tabaci (Genn.) (Hemiptera Homoptera: Aleyrodidae). Bull, entomol. soc. Egypt 1970.53: 339-35

6. Coudriet D.L., Prabhaker N. and Meyerdirk D.E. 1985. Sweet potato whitefly (Homoptera: Aleyrodidae): Effect sof neem-seed extracto novi positionan dimmaturestages. Environ. Entomol. 14: 776-779.

7. Shivanna BK, Nagaraja DN, Manjunatha $M$, Naik MI. Seasonal incidence of sucking pests on transgenic Bt cotton and correlation with weather factors.
Karnataka Journal of Agricultural Sciences. 2009; 22 (3): 666-667.

8. Selvaraj S, Ramesh V. Seasonal abundance of whitefly, Bemisia tabaci Gaennadius and their relation to weather parameters in cotton. International Journal of Food, Agriculture and Veterinary Sciences. 2012; 2 (3) -57-63.

9. Sulaymonov O.A., Khakimov A.A. CITRUS PEST - CITRUS WHITEFLY (DIALEURODES (ITRI) / Recommended to another Scientific and Technological Council of the Preslidnoy station "Mayak" to the Institute of Vegetables and Production of the National Academy of Sciences of Ukraine. Vidpovidalny for the issue: they say. sciences. spivrob. Poznyak OV. - 2018. -- p. 243-247.

10. Sulaymonov O.A., Khakimov A.A., Dusmurodova G.T. Harm of sucking pests of citrus crops // EURASIAN UNION OF SCIENTISTS (ESU). - 2020. - p. 31-33.

11. Kimsanboev Kh.Kh., Sulaimonov O.A. The effectiveness of the use of the drug nistar against the sucking pests of cotton // Bulletin of agrarian science of Uzbekistan. - 2017.-- p. 59-63. 